\title{
THE POTENTIODYNAMIC BEHAVIOUR OF IRON IN ALKALINE SOLUTIONS
}

\author{
R. S. Schrebler Guzmán, J. R. Vilche and A. J. Arvía \\ Instituto de Investigaciones Fisicoquímicas Teóricas y Aplicadas, División Electroquímica, \\ Sucursal 4, Casilla de Correo 16, 1900 La Plata, Argentina
}

(Received 15 May 1978; and in revised form 2 October 1978)

\begin{abstract}
The potentiodynamic behaviour of iron in alkaline solutions under carefully controlled perturbation conditions reveals that the overall electrochemical process is more involved than was thought earlier. The electrochemical characteristics of the systems are explained through a series of successive conjugated redox couples principally involving $\mathrm{Fe}(\mathrm{OH}), \mathrm{Fe}(\mathrm{OH})_{2}$ and $\mathrm{FeOOH}$ as limiting stoichiometric species. The yield of soluble species such as either $\mathrm{FeO}_{2}^{2-}$ or $\mathrm{HFeO}_{2}^{-}$increases with the pH. Ageing effects of reactants and products are also distinguished through the potentiodynamic $E / I$ records.
\end{abstract}

\section{INTRODUCTION}

The literature on the electrochemistry of the Fe/alkaline solution interfaces is relatively extensive since the knowledge of their behaviour is important for many applications covering the technology of alkaline accumulators and corrosion and protection of iron and steel. The pertaining literature has been reviewed in several publications[1-5]. Since the beginning of the century the nature of the products formed at those interfaces, either spontaneously or under an anodic polarization, as well as the kinetics and mechanisms of the corresponding processes have been investigated[6-9]. To explain the steady state anodic dissolution of iron in alkaline solution a consecutive reaction mechanism was proposed by Kabanov et al [10] which should be considered as an important milestone in the understanding of the processes involved and their kinetics. There is no doubt that metallic iron undergoes at least two successive electrochemical reactions during the anodization of the interface. The structures of the resulting products, although studied by many authors using different optical techniques[11-15], were not unambiguously determined. However, the anodic oxidation products in $5 \mathrm{~N} \mathrm{KOH}$, as investigated by sem techniques, correspond to $\mathrm{Fe}(\mathrm{OH})_{2}$ on the first discharge and on continued discharge the product becomes a sludge, probably consisting of hydrated FeOOH[11].

Nevertheless, the kinetic interpretation of the reactions at the $\mathrm{Fe} /$ alkaline solution interfaces becomes perhaps more involved than was thought earlier, particularly after the results obtained for the interface perturbed with systematically changed potential-time programs are considered. Most of the results obtained with potentiodynamic techniques reported in the literature are not completely reproducible, probably because only a fraction of the possible adjustable variables were kept under control. However, from each particular set of experimental data, different and sometimes contradictory interpretations and reaction models were advanced $[3,4,10,16-24]$.

At present, the electrochemistry of the $\mathrm{Fe} /$ alkaline solution interfaces poses several questions for dis- cussion, such as the influence of each variable on the electrochemical relaxation techniques and on the resulting data, the actual number of potentiodynamic current peaks as well as the number of conjugated oxidation/reduction peaks involved under particular perturbation conditions, the influence of the hydrogen evolution reaction on the iron electrooxidation and to what extent the metal electrooxidation reaction proceeds through a precipitation-dissolution mechanism.

The present report presents the results obtained from potentiodynamic experiments under controlled conditions in an attempt to contribute to answer the questions referred to above. $A$ reaction model to explain the electrochemical behaviour of the Fe/alkaline solution interfaces is then proposed.

\section{EXPERTMENTAL}

The experimental setup was the same already described in the previous publications related to the electrochemical behaviour of nickel electrodes in aqueous solutions $[25,26]$. "Specpure" iron wires $(0.5 \mathrm{~mm}$ dia., Johnson Matthey Chem. Ltd with the following impurities in ppm: $\mathrm{Mn}, 3 ; \mathrm{Ca}, 2 ; \mathrm{Si}, 2 ; \mathrm{Cu}, 1$ and $\mathrm{Mg}$ less than 1) were employed. The following electrolyte solutions were used: $1.00 \mathrm{~N} \mathrm{KOH} ; 0.10 \mathrm{~N} \mathrm{KOH}$; $0.10 \mathrm{~N} \mathrm{KOH}+0.60 \mathrm{~N} \mathrm{~K}_{2} \mathrm{SO}_{4} ; 0.01 \mathrm{~N} \mathrm{KOH}+$ $0.66 \mathrm{~N} \mathrm{~K}_{2} \mathrm{SO}_{4}$. They were prepared from triply distilled water and analytical grade (Merck) reagents. Experiments were made under $\mathrm{N}_{2}$ gas saturation at $25^{\circ} \mathrm{C}$ using triangular potential scans either single (STPS) or repetitive (RTPS) between the cathodic and anodic switching potential limits $\left(E_{\lambda, c}\right.$ and $E_{\lambda, a}$, respectively) and other different potential/time perturbations which are indicated for each particular experiment. Potentials were measured against a saturated calomel electrode but they are all referred to the nhe scale.

\section{RESULTS}

An iron electrode in contact with $1.0 \mathrm{~N} \mathrm{KOH}$ spontaneously attains a rest potential $\left(E_{r}\right)$ of -0.065 $\pm 0.005 \mathrm{~V}$. The switching potentials of the potentio- 
dynamic perturbations $\left(E_{\lambda, c}\right.$ and $\left.E_{\lambda, a}\right)$ were fixed independently of the rest potential. As already reported in potential sweep studies of iron in $1 \mathrm{M}$ $\mathrm{KOH}$ [4], in $1 \mathrm{M} \mathrm{LiOH}$ [3], in $0.4 \mathrm{M} \mathrm{Na}_{2} \mathrm{SO}_{4}+0.1 \mathrm{M}$ $\mathrm{NaOH}[24]$ and in $0.075 \mathrm{M} \mathrm{Na} \mathrm{B}_{4} \mathrm{O}_{7}+0.3 \mathrm{M}$ $\mathrm{H}_{3} \mathrm{BO}_{3}[27]$ the reproducibility of the electrochemical response was improved by first briefly holding the potential of the interface well into the hydrogen evolution region (for instance $5 \mathrm{~min}$ at $-1.16 \mathrm{~V}$ ) in order to reduce oxides which spontaneously formed on the metal surface prior to the potential excursion to positive potentials and back. The $E / I$ contour was unaffected either by further increasing the negative potential or by holding the potential for a longer time.

The $E / I$ displays obtained with RTPS at $0.1 \mathrm{~V} / \mathrm{s}$ in $1 \mathrm{~N} \mathrm{KOH}$ solution within the potential range $E_{\lambda, c}=$ $-1.16 \mathrm{~V}$ and $E_{\lambda, a}=0.73 \mathrm{~V}$ using a polished iron electrode, after a cathodization at $E_{\lambda, c}$ during $5 \mathrm{~min}$, exhibit a complex contour which changes during cycling (Fig. 1). Four anodic current peaks at about $-0.78 \mathrm{~V}$ (Peak I), $-0.62 \mathrm{~V}$ (Peak II), $-0.36 \mathrm{~V}$ (Peak III) and $-0.16 \mathrm{~V}$ (Peak III') are distinguishable during the first positive-going excursion. The immediately returning negative-going scan exhibits two cathodic current peaks at about $-0.85 \mathrm{~V}$ (Peak IV) and -1.03 V (Peak V), respectively. Current peak III' $^{\prime}$ appears as a broad shoulder of current peak III, which is poorly defined in the first cycle. Current peak IV is a relatively wide and asymmetric current peak with an appreciable cathodic current contribution at the positive potential side (current peak IV'). The following successive potential sweeps show a slight decrease of the anodic current peaks I and II, the magnification of both the anodic current peak III and the cathodic current peak IV, and the decrease of the cathodic current peak $V$. In the following text the individual characteristics of each current peak is considered.

The anodic current during the positive-going potential excursion after passing the third anodic peak, decreases to a relatively small value and remains constant over a potential of almust $1 \mathrm{~V}$ before it increases abruptly. The returning excursion within the same potential range exhibits practically the same characteristics for the cathodic current. The anodic current increase beyond $0.61 \mathrm{~V}$ corresponds to the oxygen evolution reaction.

In general, the height of current peak I attains a stable profile when the number of potentiodynamic cycles $(n)$ is $n>20$. For $E_{\lambda, c}$ less than $-1.1 \mathrm{~V}$, the height of current peak I obtained at the first and at the $n$th cycle remains practically unchanged after a polarization time $(\tau)$ at $E_{\lambda, c}, \tau \geqslant 2 \mathrm{~min}$. For $E_{\lambda, r}$ more positive than $-1.1 \mathrm{~V}$ the decrease of the peak height during cycling is more pronounced when $E_{\lambda, r}$ is increased. Simultaneously, the current peak potential $\left(E_{p, \mathrm{~L}}\right)$ slightly shifts towards more positive potentials. The first positive-going scan of the $E / I$ displays run from $E_{\lambda, c}=-1.0 \mathrm{~V}$ to $E_{\lambda, a}=0.0 \mathrm{~V}$ exhibits the already referred to characteristics but for the following positive-going potential excursions $(n>2)$ only an anodic current peak is observed (Fig. 2).

Each cycle of the experiments with RTPS at $0.2 \mathrm{~V} / \mathrm{s}$ include a previous potentiostat value of $E_{\lambda, \mathrm{c}}=$ $-1.16 \mathrm{~V}$ for $\tau=5 \mathrm{~min}$ before running the positive going potential sweeps (Fig. 3). The $E / I$ displays are entirely consistent with the measurements employing a conventional RTPS perturbation. Along the successive cycles the profile of current peak $I$ is completely reprociucible, a situation is achieved because of the previous cathodization between triangular potential scans. The changes of current peak II are reflected in the increase of current peak III. Broadly considered, current peak II under symmetric RTPS, although more poorly defined than current peak $I$, also increases with the number of cycles but it attains a stable contour faster. Under those circumstances both $I_{p .11}$ and $E_{p, y}$ are independent of $E_{\lambda, a}$, although the corresponding profile is strongly influenced by the characteristics of current peak III. Current peaks III, III', IV and $V$ are modified during cycling in the way already described. The $E / I$ profile represented by the broken line in Fig. 3 (8th cycle) corresponds to an intermediate

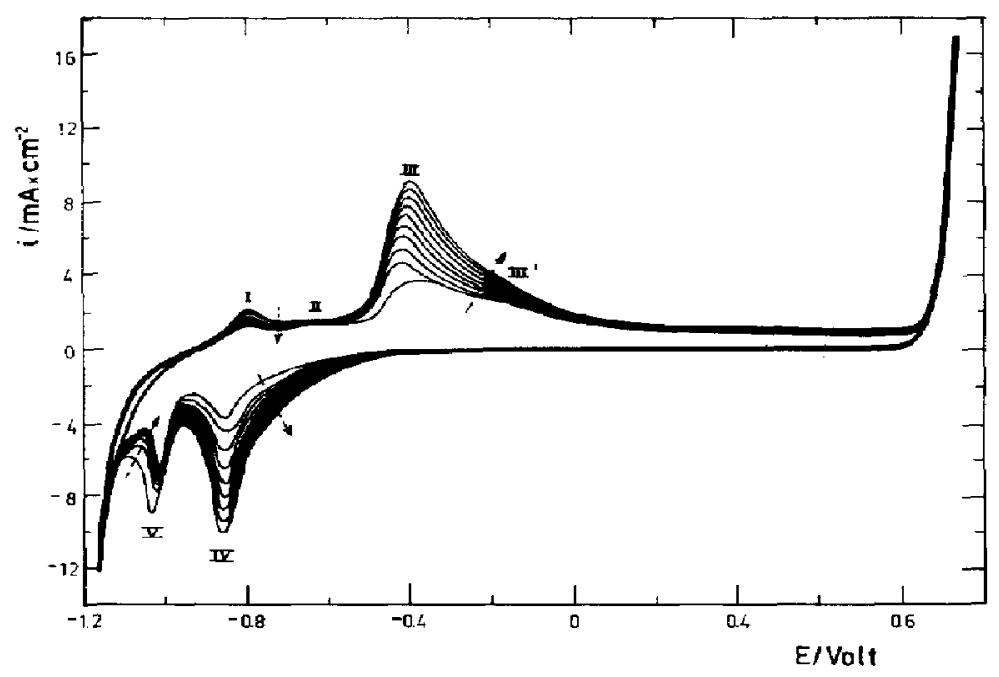

Fig. 1. $E / I$ profiles run under RTPS at $0.1 \mathrm{~V} / \mathrm{s}$ between $E_{\lambda, c}=-1.16 \mathrm{~V}$ and $E_{2, a}=0.73 \mathrm{~V}$, after a $5 \mathrm{~min}$ cathodization at $E_{\lambda, \varepsilon} .1 \mathrm{~N} \mathbf{K O H}$. The broken arrows indicate the successive potential cycles. 


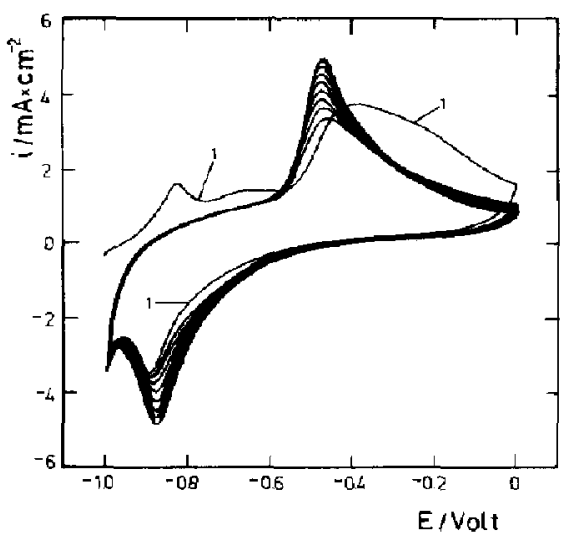

Fig. 2. $E / I$ profiles run under RTPS from $E_{\lambda, c}=-1.0 \mathrm{~V}$ to $E_{\lambda, a}=0.0 \mathrm{~V}$ at $v=0.1 \mathrm{~V} / \mathrm{s}$, after a $5 \mathrm{~min}$ cathodization at $E_{\lambda, c} 1 \mathrm{~N} \mathrm{KOH}$.

potential scan without any waiting time at $E_{\lambda, c}$. Under these circumstances the characteristics of the $E / I$ profile are the same as those depicted in Fig. 1, but the following scan ( 9 th cycle) obtained after a cathodization during $5 \mathrm{~min}$ at $E_{\lambda, c}$ repeats the characteristics of the $7 \mathrm{th}$ cycle. The negative-going potential excursions always start by exhibiting a cathodic current when the potential is more negative than the potential corresponding to the current peak III. When $E_{\lambda, a}$ extends within the passive region $(00.6 \mathrm{~V})$ then a net

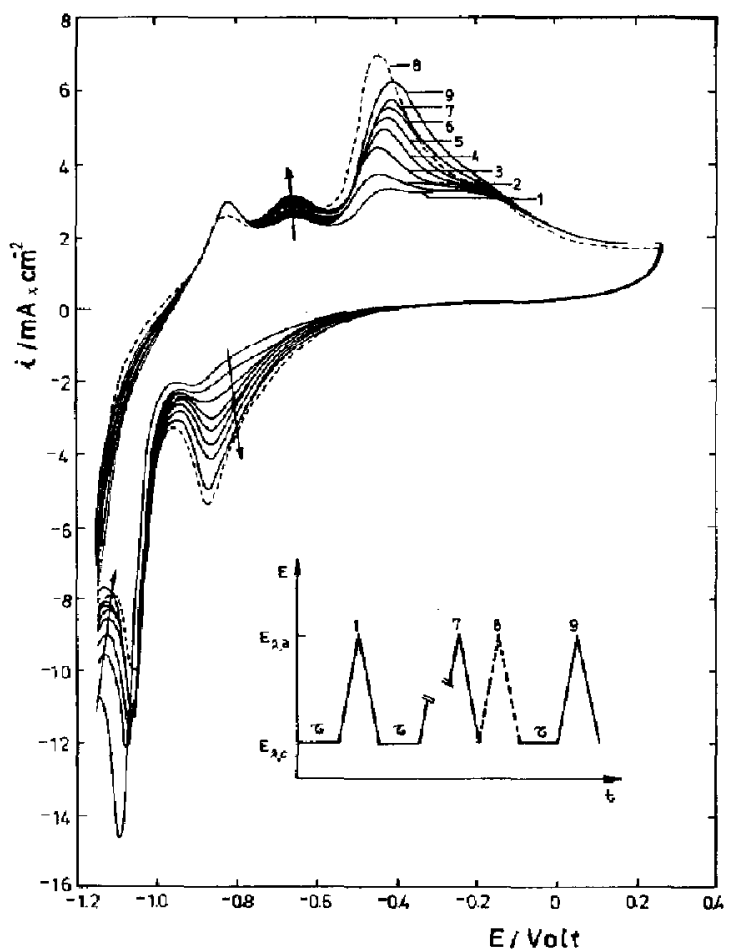

Fig. 3. E/I displays recorded with STPS at $0.2 \mathrm{~V} / \mathrm{s}$ after a $5 \mathrm{~min}$ cathodization at $E_{\lambda, c}=-1.16 \mathrm{~V}$ before each run. $1 \mathrm{~N}$ $\mathrm{KOH}$. The $E / I$ 8th cycle was obtained without the previous potentiostatting at $E_{1, c}$ as indicated in the $E / t$ programme. cathodic current appears at a potential very close to that of current peak III.

The $E / I$ displays depicted in Fig. 4 are recorded with RTPS initiated again after a 5 min cathodization at $E_{\lambda, c}$ while $E_{\lambda, a}$ is increased stepwise. The $E / I$ curve is recorded during the third RTPS after changing the $E_{\lambda, a}$ value. These $E / I$ displays show the genesis of current peaks $I, I I$ and $V$. When $E_{\lambda, a}$ is more negative than $-0.60 \mathrm{~V}$, current peak $\mathrm{V}$ is the only one which is recorded during the negative-going scan. Furthermore, the charge of the latter is undoubtedly related to those of the anodic current peaks $I$ and II. When $E_{\lambda_{-} \text {is }}$ more positive than $-0.61 \mathrm{~V}$, it is clearly seen that the charge of the current peaks III and IV are interrelated. Current peak 'II' disappears when $E_{\lambda, c}$ is more positive than $-0.60 \mathrm{~V}$. The dashed $E / I$ contours show the increase of current peaks III and IV under RTPS between fixed switching potential limits.

To evidence changes of the anodic products eventually due to either reaccommodation of the surface species or structural changes in the film, experiments involving a systematic change of either $E_{\lambda, a}\left(E_{\lambda, c}=\right.$ constant) or $E_{\lambda, c}\left(E_{\lambda, a}=\right.$ constant $)$ with a preset potentiostat time at $E_{\lambda, a}$ were made. Presumably, the effect of potentiostatting at $E_{\lambda, a}$ may be equivalent to the ageing of the electrochemically formed oxygencontaining monolayers on noble metals [28, 29].

Two different experiments including a 5 min potentiostat time at $E_{\lambda . a}$ under different conditions are depicted in Fig. 5. When the potentiostatting occurs before the initiation of the RTPS (Fig. 5(a)), there is a net change of the initial $E / I$ profile run from $E_{\lambda, a}$ downwards as compared to the following successive $E / I$ profiles. The decreasing tendency of the different current peaks are indicated by the arrows shown in the figure. The first negative-going potential scan presents another cathodic reaction (IV') at potentials more positive than the potential of current peak $V$. Otherwise, when a potentiostat time at $E_{\lambda, a}$ is included

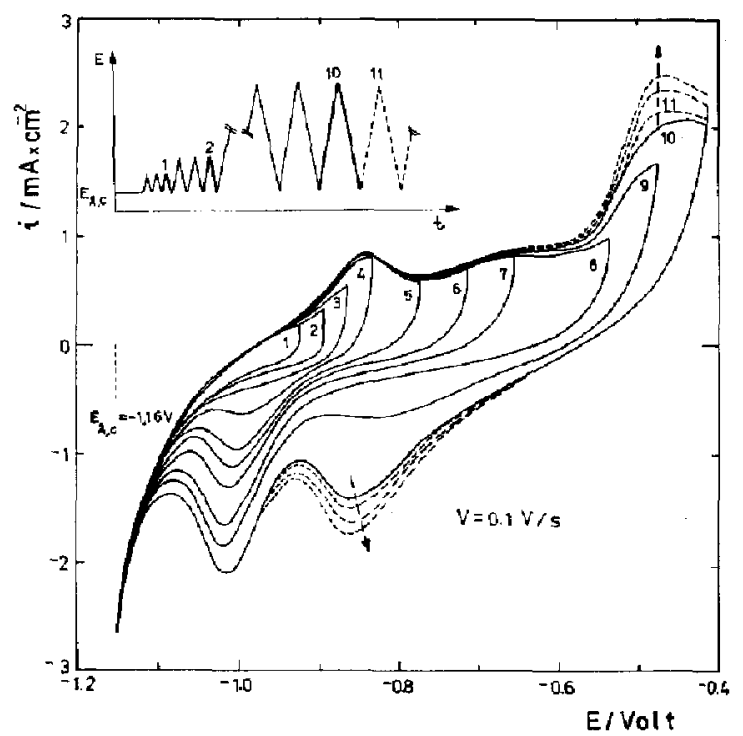

Fig. 4. Potentiodynamic $E / I$ profiles at $v=0.1 \mathrm{~V} / \mathrm{s}$ started from $E_{2, e}=-1.16 \mathrm{~V}$ under the $E / t$ programme shown in the figure. I N KOH. 


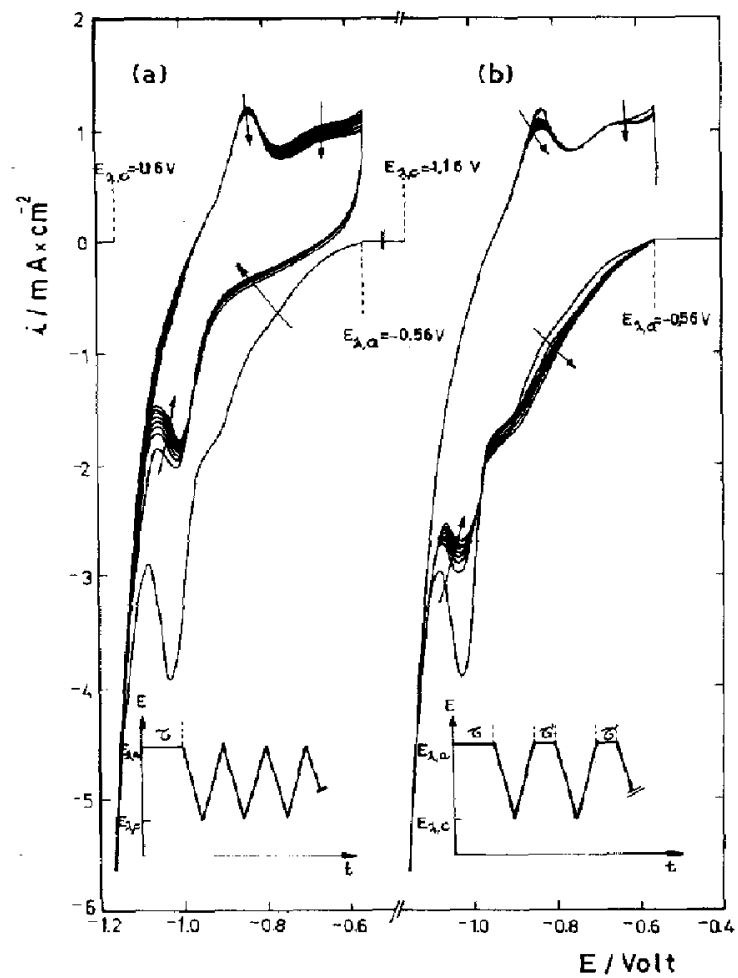

Fig. 5. Potentiodynamic $E / I$ displays obtained at $0.1 \mathrm{~V} / \mathrm{s}$ from $E_{\lambda, a}=-0.56 \mathrm{~V}$ to $E_{\lambda, c}=-1.16 \mathrm{~V}$, after a previous 5 min potentiostatting at $E_{\lambda, a}$. (a) $E / I$ curves recorded with RTPS ; (b) $E / I$ curves recorded under STPS including a $5 \mathrm{~min}$ interruption at $E_{i, a}$ before each successive cyclc. $1 \mathrm{~N}$ KOH. The arrows indicate the cycling order.

between each potential scan (Fig. 5(b)) the contribution of the cathodic reaction IV' slightly increases during cycling, whilst the responses of current peaks I and $\mathrm{V}$ remain practically the same as in Fig. 5(a). The change of the current peak II, if there is any, is not quite clear.

When the potentiostat time at $-0.16 \mathrm{~V}$ is included between the potential scans, and $E_{\lambda, c}$ is more positive than that of Fig. 5 , then the $E / I$ displays change during the potential cycling as follows. When $E_{\lambda, c}$ is more positive than the current peak IV (Fig. 6(a)) with a $10 \mathrm{~min}$ initial anodization time and $5 \mathrm{~min}$ potentiostatting at $E_{2 . a}$ between the potential scans, the successive $E / I$ displays show a decrease of both the height of current peak III and the overall cathodic current. The general effect corresponds to the electrode deactivation. On extending $E_{\lambda, c}$ towards more negative values (Fig. 6(b)) with 5 min initial anodization and 3 min potentiostatting at $E_{\lambda, a}$ between the potential scans, the $E / I$ displays exhibit an increasing contribution to the current peaks III and IV as already described. The potential perturbation; however, produces a splitting of current peak IV, the contribution of the more positive current peak becoming relatively more important during the potential cycling.

To evaluate the influence of $E_{\lambda, \mathrm{r}}$ on the $E / I$ profile in the potential range of current peaks $I$ and $V$ (Fig. 7) each $E / I$ display was obtained after a previous RTPS

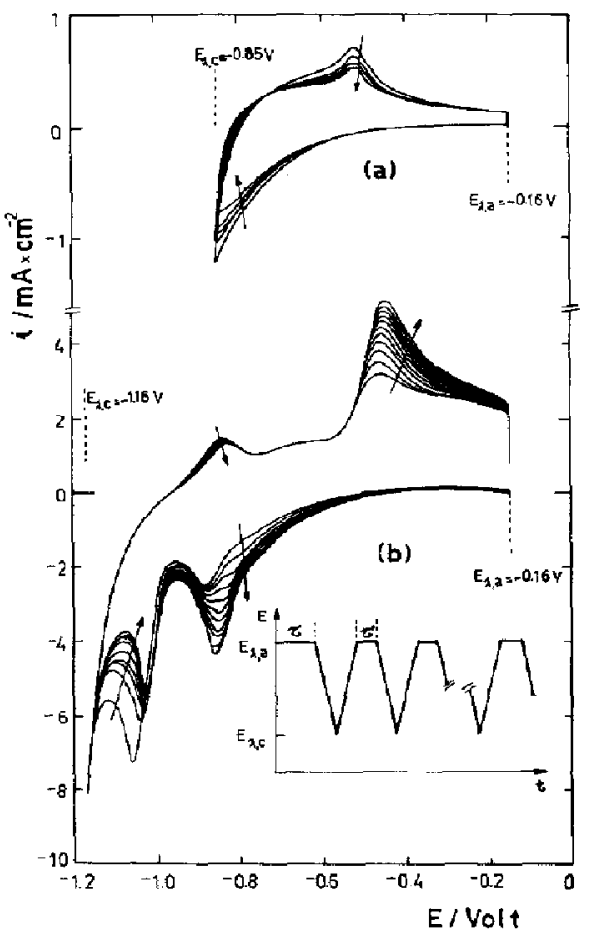

Fig. 6. Potentiodynamic $E / I$ displays obtained at $0.1 \mathrm{~V} / \mathrm{s}$ from $E_{\lambda, \text { a }}=-0.16 \mathrm{~V}$ to different $E_{\lambda, c}$ values, after $\tau$ min potentiostatting before recording each successive cycle. $1 \mathrm{~N}$ KOH. (a) $E_{\lambda, c}=-0.85 \mathrm{~V}, \tau=10 \mathrm{~min}, \tau=5 \mathrm{~min}$; (b) $E_{\lambda, c}=$ $-1.17 \mathrm{~V}, \tau=5 \mathrm{~min}, \tau^{\prime}=3 \mathrm{~min}$.

between $-1.16 \mathrm{~V}$ and $-0.76 \mathrm{~V}$ to attain firstly a stabilized $E / I$ contour. This was immediately followed by a STPS between $E_{\lambda . a}$ and the variable cathodic switching potential $\left(E_{\lambda, c}^{\prime}\right)$ which is more positive than the one used during the RTPS. These displays show

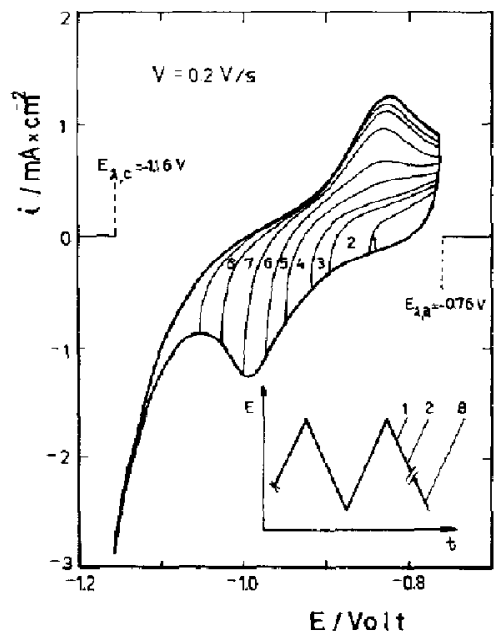

Fig. 7. Dependence of the $E / I$ profiles on the cathodic switching potential. Each run was made after a previous RTPS at $0.2 \mathrm{~V} / \mathrm{s}$ between $-1.16 \mathrm{~V}$ and $-0.76 \mathrm{~V}$ to attain a stabilized E/I contour. $1 \mathrm{~N}$ KOH. 
the genesis of current peak I as well as the separation of the electrochemical processes related to the anodic current peaks I and II. One also observes that as the cathodic switching potential $\left(E_{\lambda, c}^{\prime}\right)$ approach the $E_{\lambda, c}$ value then the hydrogen evolution region begins to be covered, the latter reaction has no appreciable influence in the potential range of current peak $I$. When similar experiments are made after extending the anodic switching potentials towards more positive values, the genesis of the different peaks are clearly seen (Fig. 8(a)). Furthermore, as $E_{\lambda, c}^{\prime}$ is changed towards $E_{\lambda_{1,}}$, then the more negative $E_{\lambda, c}^{\prime}$ the higher the irreversibility of the process in the $-0.4 \mathrm{~V}$ to $-0.8 \mathrm{~V}$ range is, as deduced from the initial slope of the $E / I$ curve at the switching potential. Contrarily, at $E_{\lambda, a}$ the electrode is remarkably more active. Similar experiments including a variable anodic switching potential ( $\left.E_{\lambda, a}^{\prime}\right)$ (Fig. 8(b)) show the shifts of the current peaks IV and $\mathrm{V}$ towards more negative potentials as $E_{\lambda_{a} a}^{\prime}$ approaches $E_{\lambda_{1, a}}$.

To determine the influence of voltage sweep rate, $v$, on the different stabilized $E / I$ profiles, runs were made between switching potentials covering only the potential range of the different current peaks (Figs 9-11). The $E / I$ profiles exhibit characteristic isopotentials defined at $I=0$. The isopotentials depend on the switching potential values.

Due to the complex characteristics of the $E / I$ contours, it is difficult to derive quantitative kinetic data from the functional dependences of the different electrochemical and perturbation parameters. These relationships are, however, obtained for each current peak when ever possible, both for the first potentiodynamic cycle and for the $n$th RTPS where a stable contour is supposedly attained. Double layer capacities $\left(C_{d l}\right)$ for metal electrodes in aqueous solutions are usually less than $100 \mu \mathrm{F} / \mathrm{cm}^{2}$. Thus, for an area $(A)$ of $0.25 \mathrm{~cm}^{2}$ and a potential sweep rate of $0.1 \mathrm{~V} / \mathrm{s}$, the

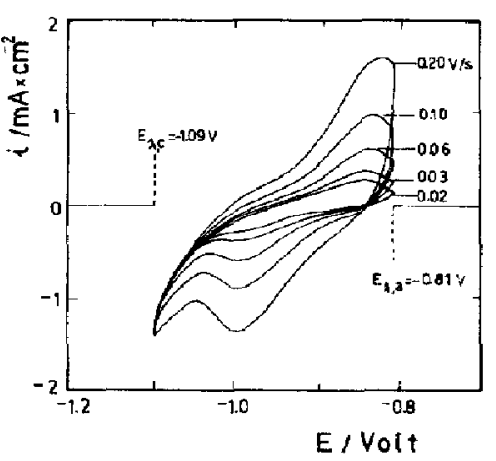

Fig. 9. Stabilized potentiodynamic $E / I$ displays obtained with RTPS between $-1.09 \mathrm{~V}$ and $-0.81 \mathrm{~V}$ at different potential sweep rates. $1 \mathrm{~N}$ KOH.

non-faradaic contribution $\left(C_{d t} A v\right)$ to the total current should not exceed $2.5 \mu \mathrm{A}$. This correction is therefore negligible. Thus, the observed current arises almost entirely from the faradaic processes occurring at the metal surface. Therefore, one can derive the various dependences, either at constant $\mathrm{pH}$ or at a constant voltage sweep rate, which are assembled in Tables 1-3.

A few comments about these data seem to be pertinent. Most of those figures are practically independent of either $E_{\lambda, a}$ or $E_{\lambda . c}$. The $E / I$ contour involving current peaks I and II stabilizes relatively fast during cycling so that the influence of $v$ on the stable profile was determined at $0.03 \mathrm{~V} / \mathrm{s} \leqslant v \leqslant$ $0.3 \mathrm{~V} / \mathrm{s}$. During cycling the $\left(\partial \log I_{p, v} / \partial \log v\right)$ ratio decreases as $n$ increases. Under these circumstances, the experimental data are probably influenced to a large extent by the changes produced on current peak IV during cycling. Otherwise, the height of current peak III is principally influenced by $E_{\lambda, c}$. Thus, when

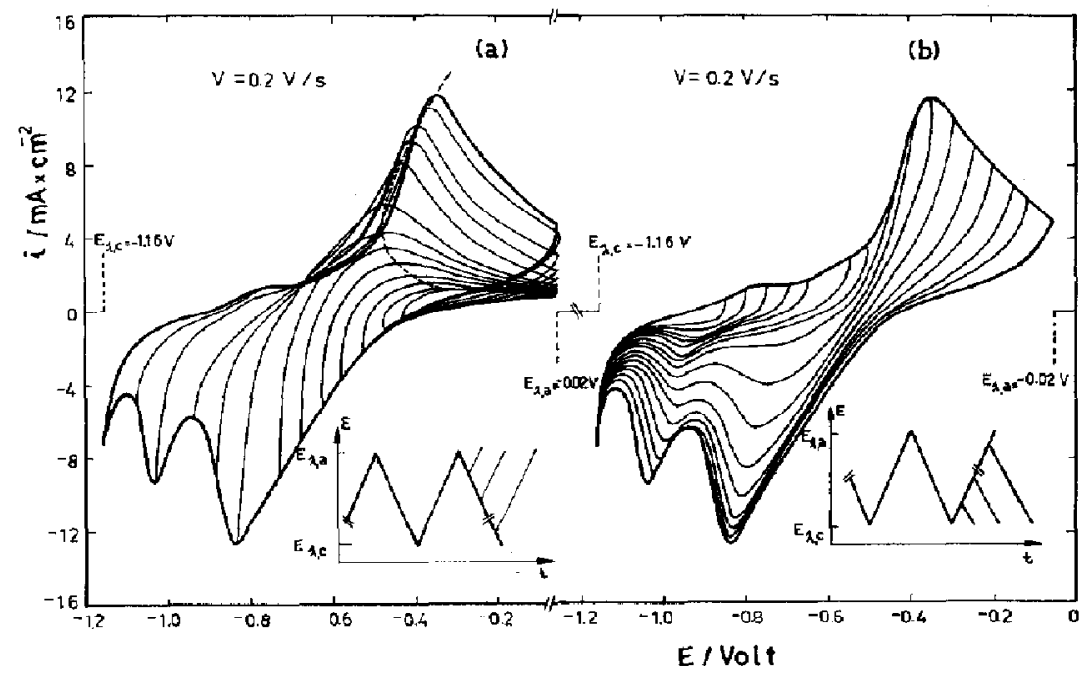

Fig. 8. Influence of the switching potentials on the potentiodynamic $E / I$ contour at $0.2 \mathrm{~V} / \mathrm{s} .0 .1 \mathrm{~N} \mathrm{KOH}+$ $0.6 \mathrm{NK}_{2} \mathrm{SO}_{4-}$ (a) Each run was made by changing $E_{l, c}$ upwards after a previous $\mathrm{RTPS}$ between $-1.16 \mathrm{~V}$ and $-0.02 \mathrm{~V}$, to attain a stable $E / I$ profile; (b) Each run was made by changing $E_{\lambda .4}$ downwards after the same RTSP conditions described above. 


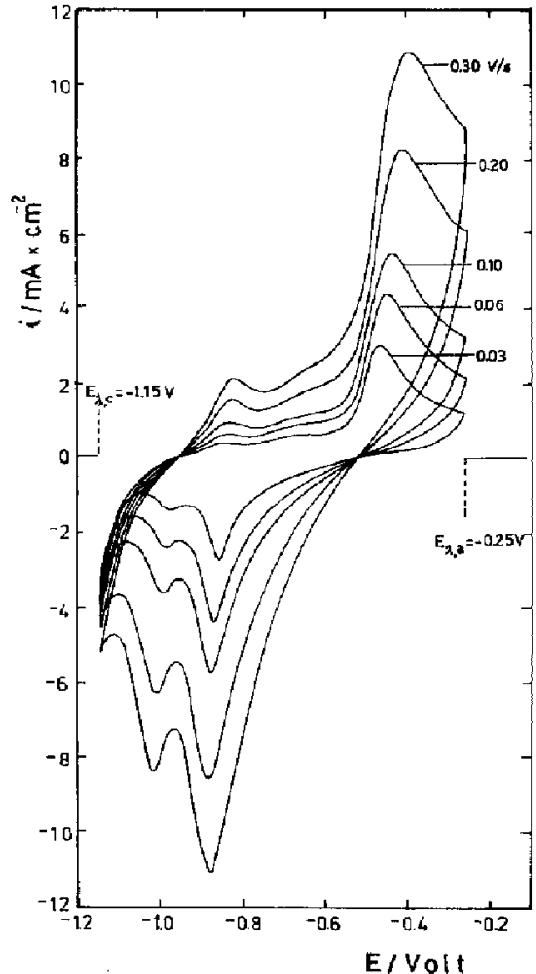

Fig. 10. Stabilized potentiodynamic $E / I$ displays recorded with RTPS at different potential sweep rates in the $-1.15 \mathrm{~V}$ to $-0.25 \mathrm{~V}$ potential range. $1 \mathrm{~N} \mathbf{K O H}$.

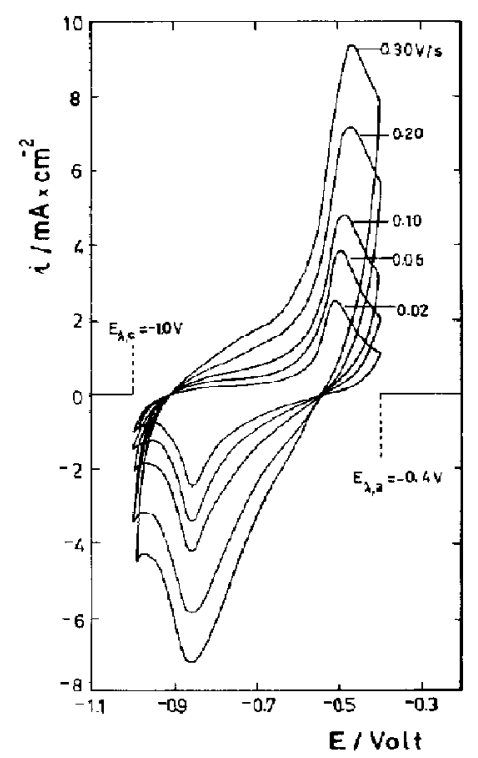

Fig. 11. Stabilized potentiodynamic E/I displays obtained with ATPS between $E_{\lambda, c}=-1.0 \mathrm{~V}$ and $E_{\lambda, 0}=-0.4 \mathrm{~V}$ at different potential sweep rates. $1 \mathrm{~N} K \mathrm{KOH}$.

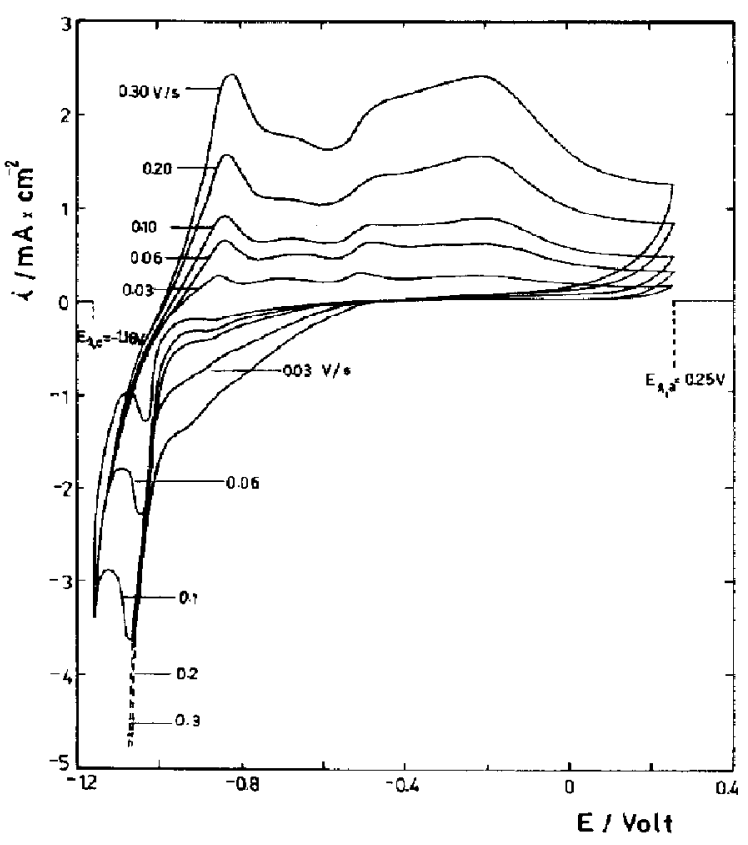

Fig. 12, Potentiodynamic $E / I$ profiles run with STPS, at $0.1 \mathrm{~V} / \mathrm{s}$ from $-1.16 \mathrm{~V}$ to $-0.25 \mathrm{~V} .1 \mathrm{~N} \mathrm{KOH}$.

Table 1. Kinetic parameters derived from the first $E / I$ profile

\begin{tabular}{lcc}
\hline $\begin{array}{c}\text { Peak } \\
\text { number }\end{array}$ & $\begin{array}{c}\left(\partial E_{\mathrm{p}} / \partial \log v\right)_{\mathrm{pH}} \\
(\mathrm{V})\end{array}$ & $\left(\partial \log i_{\mathrm{p}} / \partial \log v\right)_{\mathrm{pH}}$ \\
\hline I & $0.040 \pm 0.005$ & $0.9 \pm 0.1$ \\
II & $0.030 \pm 0.005$ & $0.9 \pm 0.1$ \\
III & $0.050 \pm 0.010$ & $0.8 \pm 0.1$ \\
III & $0.045 \pm 0.005$ & $1.0 \pm 0.1$ \\
IV & $-0.045 \pm 0.005$ & $0.9 \pm 0.1$ \\
V & $-0.070 \pm 0.010$ & $0.9 \pm 0.1$ \\
\hline
\end{tabular}

Table 2. Kinetic parameters derived from the RTPS ( $n$ thcycle)

\begin{tabular}{lcc}
\hline $\begin{array}{c}\text { Peak } \\
\text { number }\end{array}$ & $\begin{array}{c}\left(\partial E_{\mathrm{p}} / \partial \log v\right)_{\mathrm{pH}} \\
(\mathrm{V})\end{array}$ & $\left(\partial \log i_{\mathrm{p}} / \partial \log v\right)_{\mathrm{pH}}$ \\
\hline I & $0.30 \pm 0.01$ & $0.9 \pm 0.1$ \\
III & $0.07 \pm 0.01$ & $0.6 \pm 0.1$ \\
IV & $-0.03 \pm 0.01$ & $0.6 \pm 0.1$ \\
V & $-0.04 \pm 0.01$ & $0.6 \pm 0.1$ \\
\hline
\end{tabular}

Table 3. Influence of the $\mathrm{pH}$ on the kinetic parameters

\begin{tabular}{lcc}
\hline $\begin{array}{c}\text { Peak } \\
\text { number }\end{array}$ & $\left(\partial E_{p} / \partial \mathrm{pH}\right)_{\mathrm{v}}$ & $\left(\partial \log i_{\mathrm{p}} / \partial \mathrm{pH}\right)_{\mathrm{v}}$ \\
\hline I & $-0.06 \pm 0.01$ & $0 \pm 0.1$ \\
III & $-0.07 \pm 0.01$ & $0 \pm 0.1$ \\
IV & $-0.05 \pm 0.01$ & $0 \pm 0.1$ \\
V & $-0.02 \pm 0.01$ & $0 \pm 0.1$ \\
\hline
\end{tabular}


$E_{\lambda, c}$ is more positive than $-1.2 \mathrm{~V}$ its height decreases during the potential cycling and its potential slightly increases. Contrarily, when $E_{\lambda, c}$ is more negative than $-1.2 \mathrm{~V}$, the reverse effect is seen. The anodic current contribution at the positive potential side of peak III is more noticeable as $E_{\lambda, c}$ decreases and it is practically absent when $E_{\lambda . c}$ is more positive than $-1.2 \mathrm{~V}$. By fixing adequate values for $E_{\lambda .4}$ and $E_{\lambda . e,}$ a stable $E / I$ profile is reached after about 80 cycles. Under these circumstances, the kinetic parameters reported in the Tables are obtained. The same observation is also valid for current peak IV.

On the other hand, taking into account that the distribution and position of the different current peaks depend on the perturbation program, principally when potentiostatting at presel times and with definite potential values, the mechanistic significance of the kinetic parameters derived from the potentiodynamic experiments cannot be straightforwardly envisaged.

\section{DISCUSSION}

During the successive potentiodynamic sweeps no drastic change of either the anodic or the cathodic charge is noticed. This suggests that the electrode roughness factor remains practically unchanged and that the overall electrochemical process comprises anodic and cathodic complementary processes. However, individually considered, each of those processes implies different conjugated oxidation/reduction couples within certain well defined ranges of potential.

From the present study based upon the systematic change of the perturbation variables, the following conjugated oxidation/reduction current peak correlation is established. Current peaks I and, in part, current peak II are closely related to current peak V. The correlation between current peaks II and $V$ is clearly established from the influence of $E_{\lambda, a}$. Current peak III is definitely related to current peak IV while current peak $\mathrm{III}^{r}$ is related to current peak $\mathrm{IV}^{\prime}$, where peak IV' is the cathodic current contribution at the anodic side of current peak IV. Therefore, the number of current peaks and shoulders as well as their corresponding correlations are to some extent different from those reported earlier by other authors $[3,23,24]$.

Current peak I has been attributed to the electrooxidation of adsorbed hydrogen on the electrode surface $[23,24]$. Contrarily, the interdependence of current peaks I and $V$ as described here, supports the view that current peak I should be attributed to the earlier stages of iron electrooxidation, probably to $\mathrm{Fe}(\mathrm{OH})_{2}$ species as earlier suggested[3]. It is likely that both current peaks I and II involve the electrooxidation of iron to $\mathrm{Fe}$ (II) species, while current peak $\mathrm{V}$ should correspond to the conjugated reaction. An interesting feature of current peak $\mathrm{V}$ is that its height diminishes as the number of potential scans increase. Correspondingly, its peak potential becomes more positive. This effect, which is more remarkable when $E_{k, 0}$ increases shows evidence of the existence of nonequilibrium states related to both reactants and products participating in the reaction. Moreover the separation between the electroreduction current peak $V$ and the hydrogen evolution current is larger during the first cathodic potential scan. When the number of sweeps increases, these reactions, however, seem to overlap each other. The effect is similar to that already reported for a temperature decrease from $25^{\circ} \mathrm{C}$ to $0^{\circ} \mathrm{C}$, under slow potentiodynamic perturbations [1].

From these results two important conclusions are derived. Firstly they evidence the existence of nonequilibrium states related to the participation of the reactant in the electroreduction reaction. This means that the surface species undergoes chemical changes during the potentiodynamic perturbation. Secondly, the changes of the surface species probably also influences the overpotential of the hydrogen evolution reaction.

The interpretation of the reaction from the potentiodynamic data can be made on the basis that in the alkaline solution, the stable product firstly formed in the potential range of current peaks $I$ and II is $\mathrm{Fe}(\mathrm{OH})_{2}$. This substance is then electrooxidized on the second discharge level, in the potential range of current peak III to FeOOH. This sequence of reactions is sustained by the results obtained with the X-ray diffraction and sem techniques[1] at the iron/alkaline solution interface. Those two products consecutively formed, may transform into other more stable species through a chemical reaction involying stoichiometric changes, or through structural rearrangements equivalent to those assigned to ageing effects, they also participate in the corresponding equilibria with the soluble species $\mathrm{HFeO}_{2}^{-}$and $\mathrm{FeO}_{2}^{2-}$. Therefore, the mechanism of iron corrosion and passivation in $\mathrm{KOH}$ solutions under the potentiodynamic conditions can be put forward in terms of a reaction sequence containing only hydroxo- and oxo-species entering different proton transfer processes, as follows:

$$
\begin{aligned}
\mathrm{Fe}+\mathrm{OH}^{-} & =[\mathrm{Fe}(\mathrm{OH})]_{\mathrm{ad}}+e \\
{[\mathrm{Fe}(\mathrm{OH})]_{\mathrm{ad}} } & =[\mathrm{Fe}(\mathrm{OH})]_{\mathrm{ad}}^{+}+e \\
{[\mathrm{Fe}(\mathrm{OH})]_{\mathrm{ad}}^{+}+\mathrm{OH}^{-} } & =\left\{\mathrm{Fe}(\mathrm{OH})_{2}\right\} \\
\left\{\mathrm{Fe}(\mathrm{OH})_{2}\right\}+\mathrm{OH}^{-} & =\mathrm{HFeO}_{2}^{-}+\mathrm{H}_{2} \mathrm{O} \\
\mathrm{HFeO} & -\mathrm{OH}^{-} \\
= & \mathrm{FeO}_{2}^{2-}+\mathrm{H}_{2} \mathrm{O} \\
\left\{\mathrm{Fe}(\mathrm{OH})_{2}\right\}+\mathrm{OH}^{-} & =\{\mathrm{FeOOH}\}+\mathrm{H}_{2} \mathrm{O}+e \\
\{\mathrm{FeOOH}\}+\{\mathrm{FeOOH}\} & =\left\{\mathrm{Fe}_{2} \mathrm{O}_{3} \cdot \mathrm{H}_{2} \mathrm{O}\right\} .
\end{aligned}
$$

The brackets denote reaction intermediates whose surface coverage is of the order of a fraction of the monolayer and the braces indicate species eventually related to the formation of new phases and which may undergo ageing. The $\mathrm{Fe}(\mathrm{OH})_{2}$ formation through steps (1)-(3) is the same as that already proposed for the mechanism of iron dissolution in acid media $[30,31]$. The transformation of the $[\mathrm{Fe}(\mathrm{OH})]^{+}$ intermediate either to soluble $\mathrm{Fe}(\mathrm{II})$ or to $\mathrm{Fe}(\mathrm{OH})_{2}$, as given by (3), is determined by the hydrolysis constant of the ferrous ion and by the hydrogen ion activity at the metal/solution interface. The latter depends on the composition of the solution, on the location of the potential applied to the interface with respect to the pzc of the metal and on the occurrence of proton generating or proton consuming reactions at the interface. The current peak $I$ appears to be specifically related to the $\mathrm{Fe}(\mathrm{OH})_{2}$ formation through the steps (1) to (3). The existence of equilibria such as (3)-(5) favours the existence of a precipitation-dissolution 
mechanism of $\mathrm{Fe}(\mathrm{OH})_{2}$ particularly in concentrated alkaline solutions as earlier suggested[9].

At this stage if the chemical changes produced either in the reactants or the products are neglected, a simple, although limited, interpretation of the kinetic parameters derived for the $\mathrm{Fe}(\mathrm{OH})_{2}$ film formation can be advanced. Thus, both the linear $I_{p .1} v s v$ and $E_{p .1} v s$ $\log v$ relationships approach, in principle, the predictions of simple reaction models involving either a monolayer formation or a layer formation at constant thickness $[32,33]$. The slope of the $E_{p, 1} v s \log v$ plot for the first potential sweep is $0.040 \mathrm{~V} /$ decade, which being independent of $v$, can be attributed to the Tafel slope of the $\mathrm{Fe}(\mathrm{OH})_{2}$ film formation process, on the assumption that the reaction intermediate follows a Langmuir adsorption isotherm under a low degree of surface coverage. Therefore, under steady state conditions step (2) is rate determining. This conclusion agrees with previous results obtained both in acid and alkaline media by different authors $[10,24,30,31]$. $\mathrm{Fe}(\mathrm{OH})_{2}$ species are also related to current peak II as deduced from the fact that the sum of the anodic charges related to current peaks I $\left(q_{a, 1}\right)$ and II $\left(q_{a, \mathrm{II}}\right)$ equals that of current peak $V\left(q_{c}\right)$. This is clearly seen during the repetitive potential scanning in which for a constant $q_{c}$ there is a progressive increase of $q_{a \text {. I }}$ and a continuous decrease of $q_{a, 1}$. The partial overlapping of current peaks I and II and the change of the $q_{a . I} / q_{a . \text { II }}$ ratio, either during the repetitive potential cyling at a constant $v$ or to some extent when $v$ changes, causes the slope $\partial \log I_{p .1} / \partial \log v$ to be slightly lower than one. Therefore, the current peak II should correspond to an electrochemical reaction yielding $\mathrm{Fe}(\mathrm{OH})_{2}$ but with the simultaneous transformation of the $\mathrm{Fe}(\mathrm{OH})_{2}$ surface layer into a more stable structure, probably represented by the three-dimensional oxide film forming reaction $[24,34]$.

$$
\begin{aligned}
\mathrm{Fe}_{3}\left\{\mathrm{Fe}(\mathrm{OH})_{2}\right\} & +2 \mathrm{OH}^{-} \\
= & 2 \mathrm{Fe}(\mathrm{OH})_{2} \text {. oxide phase }+2 e,
\end{aligned}
$$

where $\mathrm{Fe}$, stands for the substrate atom. The electroreduction of any of the $\mathrm{Fe}(\mathrm{OH})_{2}$ containing species takes place within the potential range of current peak V. The location of its current peak would depend on the average composition of the overall $\mathrm{Fe}(\mathrm{OH})_{2}$ film. At this stage the participation of any Fe(II) soluble species with the present solution composition can be ignored $[21,22]$.

The conjugated current peaks III(III') and IV(IV') are located in the potential range where the formation of $\mathrm{Fe}$ (III) species according to step (6) is thermodynamically possible, as deduced from the potential difference of the following equilibria :

$$
\begin{aligned}
\mathrm{Fe}+2 \mathrm{H}_{2} \mathrm{O}=\mathrm{Fe}(\mathrm{OH})_{2}+2 \mathrm{H}^{+}+2 e, \\
E_{\text {eq }}=0.047-0.0591 \mathrm{pH}
\end{aligned}
$$

and

$$
\begin{aligned}
& \mathrm{Fe}(\mathrm{OH})_{2}=(\mathrm{Fe} \mathrm{OOH})+\mathrm{H}^{+}+e \\
& E_{\text {oq }}=0.271-0.0591 \mathrm{pH} .
\end{aligned}
$$

The equilibrium potential difference between (9) and (10) at constant $\mathrm{pH}$ and activities of the other components equal to unity $(0.318 \mathrm{~V})$ is actually smaller than the difference between the potential of current peak $I$ and current peak II. This can be explained by the change of the $\mathrm{OH}^{-}$concentration at the interface during the potential scan due to the different faradaic processes and also because of the appreciable irreversibility of those reactions as deduced from the kinetic parameters assembled in the tables.

According to Lindström[35] (6) causes an opening of the structure at the beginning of the second oxidation stage, trivalent products having a higher density compared to that of bivalent reaction products. This effect should be related to the charge increase noticed in the conjugated oxidation/reduction current peaks during the potential cycling, independent of the potential sweep rate, at least within the range covered in the present work.

Reaction (6) also implies the participation of two reactants and the formation of two products which apparently involve the equivalent stoichiometries, but different electrochemical reactivities as deduced from the occurrence of two anodic current and two cathodic current contributions (peaks III and III' and IV and IV', respectively). Both the $I_{p, \mathrm{WI}} / I_{p, \mathrm{Wl}}$ and the $I_{p, \mathrm{IV}} / I_{p, \mathrm{IV}}$ ratios increase as $v$ increases. Once more there is evidence that within the potential range of those current peaks the potentiodynamic experiments also involve non-equilibrium species. Consequently paralIel structural transformations of these species are possible and the instantaneous concentration of each species must depend on the characteristics of the potential perturbation. This important question which again may be related to ageing effects was overlooked in earlier studies on the iron/alkaline solution interface, so that either the straightforward extension of steady state conclusions to potentiodynamic results or vice versa derived in unsatisfactory interpretations. The ageing effect of the anodic product may be explained through (7) although long term transformations such as those found during the charge/discharge cycling in alkaline iron battery electrodes involving the $\beta$-FeOOH to $\mathrm{Fe}_{3} \mathrm{O}_{4}$ reaction must also be considered [12]. The former ageing process relevant to the present circumstances should involve reactions like the $\delta$-FeOOH to $\alpha$-FeOOH conversion which interpreted the $\mathrm{X}$-ray diffractometry data together with the $\alpha-\mathrm{FeOOH}$ to $\mathrm{Fe}_{3} \mathrm{O}_{4}$ transformation[13].

A further mechanistic interpretation is at present not possible due to insufficient kinetic data for the iron electrodissolution in alkaline media. It appears, however, that (6) is faster than (3), in agreement with data reported by Armstrong and Baurhoo[21, 22]. The fast proton transfer process involved in that reaction explains precisely the relatively reversible behaviour of the $\mathrm{Fe} /$ alkaline interface for its use in alkaline storage cells.

The passivation of iron in alkaline solutions is initially produced by the formation of $\left\{\mathrm{Fe}_{2} \mathrm{O}_{3}, \mathrm{H}_{2} \mathrm{O}\right\}$. This species, however, does not represent the average composition of the passivating film since its complex three-dimensional structure comes from a variable contribution of the thre main reaction products already mentioned. The final species, after ageing, and under steady state conditions, may approach a structure such as $\mathrm{Fe}_{3} \mathrm{O}_{4}$ and hydrated $\mathrm{Fe}_{2} \mathrm{O}_{3}$ as already proposed for iron in different aqueous electrolytes [3, $11,24,36,37]$.

Finally, it is interesting to note that the interpretation here advanced for the Fe/alkaline system, 
although different in some aspects to those given earlier by other authors, keeps a close resemblance to that recently proposed for the Ni/alkaline system [38-40].

Acknowledgement - INIFTA is sponsored by the Consejo Nacional de Investigaciones Científicas y Técnicas, the Universidad Nacional de La Plata and the Comision de Investigaciones Cientificas (Provincia de Buenos Aires). This work is also partially sponsored by the SENID (Navy Research and Development Service of Argentina) and the Regional Program for the Scientific and Technological Development of the Organization of the American States.

\section{REFERENCES}

1. B. Andersson and L. Ojefors, J. electrochem. Soc. 123, 824 (1976).

2. A. J. Salkind, C. J. Venuto and S. U. Falk, J. electrochem. Soc. 111, 493 (1964).

3. D. D. Macdonatd and D. Owen, $J$. electrochem. Soc. 120, 317 (1973).

4. S. Astakura and $K$. Nobe, J. electrochem. Soc. 118, 536 (1971).

5. J. Labat, J. C. Jarrousseau and J. F. Laurent, Power Sources 3, Brighton (1970).

6. O. Faust, Z. Elektrochem. 13, 161 (1907).

7. F. Förster, Z. Elektrochem. 14, 295 (1908).

8. F. Förster and P. Herold, Z. Elektrochem. 16, 461 (1910).

9. B. N. Kabanov and D. I. Leikis, Acta phys.-chim. URSS 21, 769 (1946).

10. B. N. Kabanov, R. Burstein and A. Frumkin, Discuss. Faraday Soc. 1, 259 (1947)

11. L. Ojefors, J. electrochem. Soc. 123, 1691 (1976).

12. I. Geronov, T. Tomov and S. Georgiev, I. appl. Electrochem. 5, 351 (1975).

13. H. G. Silver and E. Lekas, J.electrochem. Soc. 117, 5 (1970).

14. T. K. Teplinskaya, N. N. Fedorova and S. A. Rozentsveig, Zh. Fiz. Khim. 38, 2176 (1964).

15. C. L. Foley, J. Kruger and C. J. Bechtold, J. electrochem. Soc. 114, $994(1967)$

16. C. V. D'Alkaine, R. Pereiro and D. J. Schiffrin, 25th ISE Meeting, Brighton, p. 727 (1974).
17. A. P. P'yankova and Z. A. Iofa, Elektrokhimiya 10, 1344 (1974).

18. V. N. Flerov and L. I. Pavlova, Elektrokhimiya 3, 621 (1967).

19. A. M. Sukhotin and K. M. Kartashova, Corros. Sci. 5, 393 (1965).

20. N. A. Hampson, R. J. Latham, A. Marshall and R. D. Giles, Electrochim. Acta 19, 397 (1974).

21. R. D. Armstrong and I. Baurhoo, J. electroanal. Chem. 34, 41 (1972).

22. R. D. Armstrong and I. Baurhoo, J. electroanal. Chem. 40, 325 (1972).

23. H. Cnobloch, D. Gröppel, W. Nippe and F.v. Sturm, Chem.-Ing.-Techn. 45, 203 (1973).

24. D. Geana, A. A. El Miligy and W. J. Lorenz, J. appl. Electrochem. 4, 337 (1974).

25. J. R. Vilche and A. J. Arvia, Corros. Sci. 15, 419 (1975)

26. J. R. Vilche and A. J. Arvia, J.electrochem. Soc. 123, 1061 (1976).

27. A. Rauscher, H. Konno and M. Nagayama, Electrochim. Acto 22, 823 (1977).

28. A. J. Calandra, N. R. de Tacconi and A. J. Arvía, J. electroanal. Chem. 49, 145 (1974).

29. C. M. Ferro, A. J. Calandra and A. J. Arvía, J. electroanal. Chem. 50, 403 (1974).

30. J. O'M. Bockris, D. Drazić and A. R. Despić, Electrochim. Acta 4, 325 (1961).

31. M. Badi, C Gabrielli, M. Keddam and $H$. Takenouti, 25th ISE Meeting. Zürich (1976).

32. S. Srinivasan and E. Gileadi, Electrachim. Acta 11, 321 (1966).

33. M. E. Martins, A. J. Calandra and A. J. Arvía, Electrochim. Acta 17, 741 (1972).

34. J. P. Hoare, 4th Int. Symp. on Passivity, Virginia (1977).

35. O. Lindström, 5th Conf. on Power Sourcets, Brighton (1974).

36. N. Sato, K. Kudo and R. Nishimura, J. electrochem. Soc. 123. 1419 (1976).

37. I. L. Rozenfeld and E. K. Oshe, Croat chem acta 44, 103 (1972).

38. J. R. Vilche and A. J. Arvia, 4th Int. Symp. on Passivity, Virginia (1977).

39. R. S. Schrebler Guzmán, J. R. Vilche and A. J. Arvia, J. appl. Electrochem. 8, 67 (1978).

40. R. S. Schrebler Guzmán, J. R. Vilche and A. J. Arvia, $J$. electrachem. Sac., (in press). 